\title{
A NOVEL APPROACH FOR DROUGHT CHARACTERIZATION BASED ON PERFORMANCE-ORIENTED SPI: AN ILLUSTRATIVE CASE OF SOUTHEASTERN ANATOLIA REGION, TURKEY
}

\author{
YILMAZ, B. \\ Manisa Vocational School of Technical Sciences, Manisa Celal Bayar University, Sehit Prof. \\ Dr. Ilhan Varank Campus, 45140 Yunusemre, Manisa, Turkey \\ (e-mail: baris.yilmaz@cbu.edu.tr) \\ (Received 26 $6^{\text {th }}$ Aug 2018; accepted $11^{\text {th }}$ Oct 2018)
}

\begin{abstract}
Drought is a main water-related natural hazard due to its features, sensitivities and effects to all sectors. According to climate change scenarios, drought hazards are expected to be more devastating, especially in arid and semi-arid regions. Drought characterization is essential to be aware of expected negative effects of droughts as well as to devise water management plans including possible mitigation measures. To this end, many drought indices have been developed for drought analysis, one of which is the Standardized Precipitation Index (SPI) that is widely used worldwide. In this study, a new drought index is proposed, namely the Drought Power Index (DPI), based on the SPI with orientation by reliability-resilience-vulnerability (RRV) concept. The use of the RRV approach with the SPI time series empowers the drought characterization by considering the frequency of drought event, drought recovery period as well as the severity of droughts-once a drought has occurred. Since the drought is identified as an unfavorable phenomenon, the DPI ranges from 0 to 1 where the higher values indicate higher drought devastating features (probability, duration and extremity of drought) and vice versa. The proposed approach is illustrated with reference to the Southeastern Anatolia Region, Turkey. The long-term (19702017) monthly precipitation data of eight meteorological stations under the operation of General Directorate of Meteorological Services of Ministry of Forestry and Water Affairs are used in the study. The 12-month SPI time series, which were later used for calculations of DPI, were obtained by the use of SPI_SL_6 software. The study revealed that there has been an increasing trend in DPI values in the basin, especially after 1993. It is concluded that the DPI is a valuable indicator for (i) spatially and temporally evaluating the drought characteristics, (ii) analysing meteorological, agricultural and hydrological drought severity with its coherent capability with SPI, (iii) ranking the regions in accordance with the drought vulnerability conditions.
\end{abstract}

Keywords: drought power index (DPI), indicators, reliability, resilience, vulnerability

\section{Introduction}

Drought is an important natural disaster, which has a wide range of negative impacts on the environment, agriculture and the economy (Man and Modra, 2008; Acikgoz, 2011; Konyali and Kiper, 2012; Gurel and Sener, 2012). It can be defined as a prolonged period of time beginning with a decrease in precipitation amount in a given region and a certain time interval; however, it is not possible to make a general definition due to its complexity, spatial and temporal variation and impacts (Heim, 2002; Wilhite and Glanz, 1985; Maracchi, 2000; Tate and Gustard, 2000; Tsakiris et al., 2007). The general approach to quantify the droughts is using indices. World Meteorological Organization (WMO) and Global Water Partnership (GWP) have given a wide and detailed literature and findings of drought indices for researchers in the domains of meteorology, hydrology, agricultural research and application, remote sensing, and water resources management (WMO and GWP, 2016). Depending on their structure, characteristics and their ability to fulfil certain criteria, some of them are used 
for a wide range of applications, while others are intended to address drought related issues in specific systems (Tigkas et al., 2018).

The Standardized Precipitation Index (SPI), suggested by McKee et al. (1993), is a broadly used drought index. In 2009, WMO recommended SPI as the main meteorological drought index that countries should use to monitor and follow drought conditions (Hayes et al., 2011).

Although it is considered as a meteorological drought index originally, it is also used in numerous studies related to hydrological and agricultural droughts. Within a broad perspective, the studies have shown that the SPI is a valuable tool to assess drought events (Ionita et al., 2016; Mishra and Desai, 2005; Szalai and Szinell, 2000; Panaitescu et al., 2014; Lloyd-Hughes and Saunders, 2002; Cancelliere et al., 2007), to detect spatial and temporal droughts (Vicente-Serrano, 2006; Livada and Assimakopoulos, 2007), to reveal recurrent floods (Seiler et al., 2002), to manage water resources in basin scale (Shokoohi and Morovati, 2011; Zhang et al., 2009) and to assess drought impact on crop production (Labudova et al., 2017; Chen et al., 2016).

On the other hand, the EPA (US Environmental Protection Agency) has proposed the use of integrated assessments of watershed health to assist managers with identifying healthy watersheds and prioritizing candidate watersheds for protection and restoration (EPA, 2014). Here, the use of performance indicators (PIs), which is a fundamental concept for developing new ways to assess and manage environmental resources, can help watershed managers to understand the behavior of the droughts.

In this study, a new drought index, the Drought Power Index (DPI), is proposed, based on the SPI with orientation by reliability-resilience-vulnerability concept (RRV), which is first used by Hashimoto et al. (1982) for evaluation of water resources system performance. The use of the RRV approach with the SPI time series empowers the drought characterization by considering the frequency of drought event, drought recovery period as well as the severity of droughts-once a drought has occurred. Additional PIs, namely maximum extent and maximum duration of drought are also added to the formulation of the DPI. These performance indicators are all valuable to judge the effects of climate change in a given watershed. Therefore, it differ from other indices (e.g. SPI) by its capability to reveal the increasing (decreasing) devastating potential of droughts, as well as the propensity of droughts in the watershed. In addition, the DPI serves to that EPA's proposition by its inherent hybrid approach. Since the drought is identified as an unfavorable phenomenon, the DPI ranges from 0 to 1 where the higher values indicate higher drought devastating features. The proposed approach is illustrated with reference to the eight different provinces in the Southeastern Anatolia Region, Turkey. By the use of DPI, it is aimed to provide a better identification of regional drought characteristic.

\section{Materials and methods}

\section{Study area and data}

The Southeastern Anatolia Region (SAR) covers 9 provinces (Adiyaman, Batman, Diyarbakır, Gaziantep, Kilis, Mardin, Siirt, Şanlıurfa and Şırnak) located on the Euphrates-Tigris Basin and upper Mesopotamia plains (Fig. 1).

The SAR provinces constitute approximately $10.7 \%$ of Turkey's total population (80.8 million, in 2018), and covers 9.7 of country's surface area, $780.6 \times 10^{3} \mathrm{~km}^{2}$ (GAP, 2018). In general, the summer season in the region is very hot and under the influence 
of dry and warm tropical air mass while the winter is warm and rainy. The average annual rainfall varies between $400 \mathrm{~mm}$ and $700 \mathrm{~mm}$, and the mean annual temperature is about $18{ }^{\circ} \mathrm{C}$, due to the high summer temperatures that approach $40{ }^{\circ} \mathrm{C}$ in daytime. The SAR holds $20 \%$ of the economically irrigable area of Turkey, while accounts for $28 \%$ of total water potential. In the fertile lands, the agriculture is the main activity, so the drought has vital importance on socio-economic development.

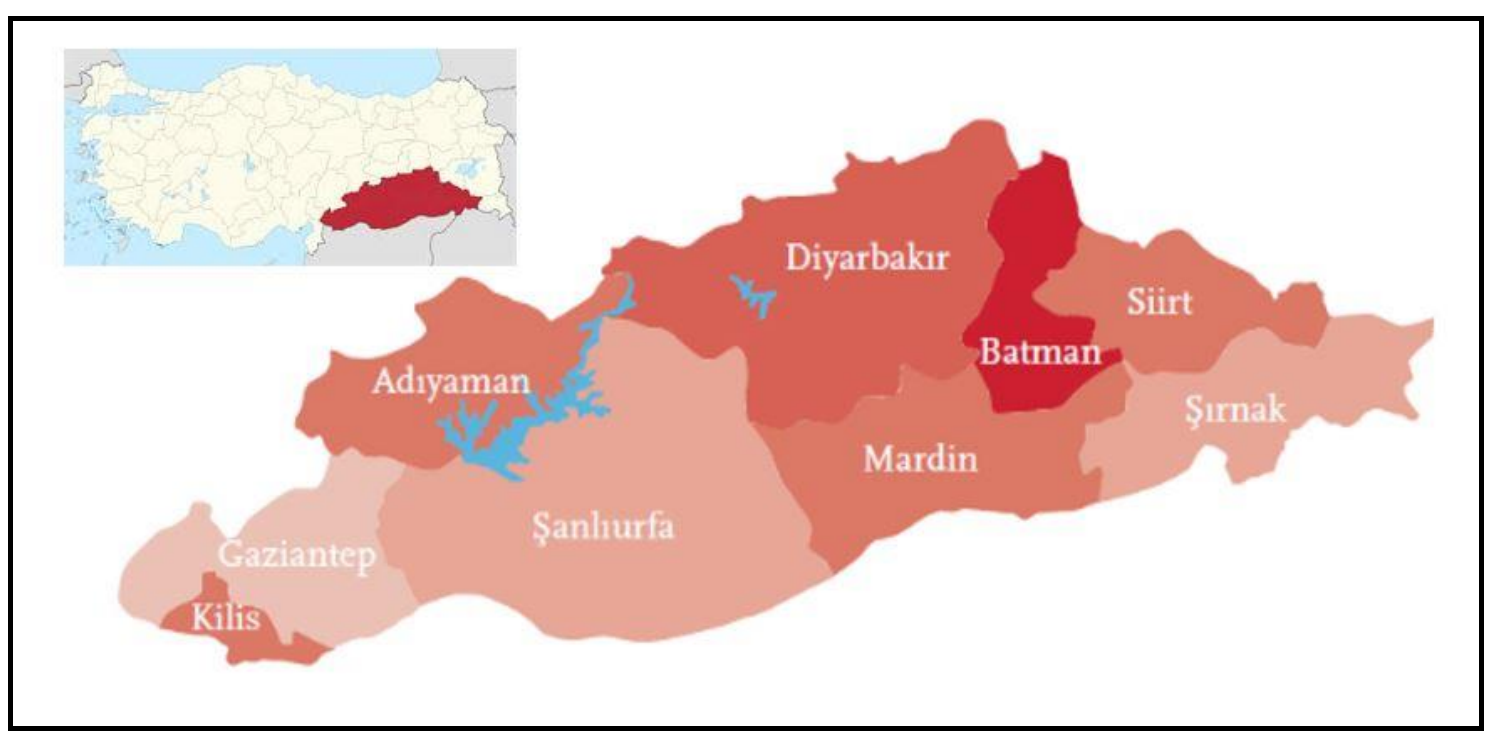

Figure 1. Location of the Southeastern Anatolia Region (SAR) and provinces in the SAR

In this study, although it was intended to calculate the DPI for the entire region, due to lack of adequate and reliable data for Şrnak, it is excluded from the analyses, and DPI values are calculated for the remaining eight provinces. Table 1 shows the geographical co-ordinates of the meteorological stations chosen in the SAR. The precipitation data monitored in the meteorological stations between 1970 and 2017 were obtained from the General Directorate of Meteorological Services of Ministry of Forestry and Water Affairs. The statistical parameters of monthly precipitation at eight stations during the study period are presented in Table 2 .

Table 1. The meteorological stations in the SAR

\begin{tabular}{c|c|c|c|c|c}
\hline Stations & Station ID & Latitude $(\mathbf{N})$ & Longitude $(\mathbf{E})$ & Elevation $(\mathbf{m})$ & Annual precip. $(\mathbf{m m})$ \\
\hline Mardin & 17275 & 37.3103 & 40.7284 & 1040 & 638 \\
Şanlıurfa & 17270 & 37.1608 & 38.7863 & 550 & 431 \\
Siirt & 17210 & 37.9319 & 41.9354 & 895 & 676 \\
Kilis & 17262 & 36.7085 & 37.1123 & 640 & 481 \\
Batman & 17282 & 37.8636 & 41.1562 & 610 & 470 \\
Gaziantep & 17261 & 37.0585 & 37.3510 & 854 & 557 \\
Adıyaman & 17265 & 37.7553 & 38.2775 & 672 & 682 \\
Diyarbakır & 17280 & 37.8973 & 40.2027 & 674 & 475 \\
\hline
\end{tabular}


Table 2. Statistical parameters of precipitation during the 1970-2017 period

\begin{tabular}{|c|c|c|c|c|c|c|c|c|c|}
\hline Months & & Mardin & Şanlıurfa & Siirt & \begin{tabular}{|l|} 
Kilis \\
\end{tabular} & Batman & Gaziantep & \begin{tabular}{|l|} 
Adıyaman \\
\end{tabular} & Diyarbakır \\
\hline \multirow{6}{*}{ January } & $\operatorname{Min}(\mathrm{mm})$ & 2.10 & 0.90 & 10.00 & 14.10 & 5.60 & 29.40 & 7.00 & 0.70 \\
\hline & $\operatorname{Max}(\mathrm{mm})$ & 233.10 & 192.40 & 196.80 & 197.30 & 128.00 & 235.60 & 333.50 & 142.80 \\
\hline & Avg. (mm) & 101.76 & 73.76 & 80.50 & 77.59 & 57.67 & 92.09 & 126.18 & 62.28 \\
\hline & $\mathrm{SD}(\mathrm{mm})$ & 61.48 & 43.86 & 37.79 & 45.83 & 26.67 & 45.69 & 69.92 & 33.92 \\
\hline & Skewness & 0.46 & 0.50 & 0.77 & 1.11 & 0.38 & 1.04 & 0.71 & 0.23 \\
\hline & Kurtosis & 0.45 & 0.48 & 0.74 & 1.07 & 0.37 & 1.01 & 0.69 & 0.22 \\
\hline \multirow{6}{*}{ February } & $\operatorname{Min}(\mathrm{mm})$ & 11.20 & 1.80 & 16.70 & 2.00 & 13.00 & 1.00 & 1.00 & 3.80 \\
\hline & $\operatorname{Max}(\mathrm{mm})$ & 241.70 & 176.90 & 189.10 & 146.20 & 141.30 & 196.60 & 233.00 & 151.80 \\
\hline & Avg. (mm) & 104.25 & 66.80 & 94.16 & 69.66 & 65.40 & 81.18 & 99.21 & 66.12 \\
\hline & $\mathrm{SD}(\mathrm{mm})$ & 59.07 & 41.18 & 41.24 & 33.15 & 29.96 & 45.23 & 53.85 & 32.40 \\
\hline & Skewness & 0.60 & 0.87 & 0.56 & 0.08 & 0.59 & 0.60 & 0.46 & 0.75 \\
\hline & Kurtosis & 0.58 & 0.85 & 0.54 & 0.08 & 0.57 & 0.58 & 0.45 & 0.73 \\
\hline \multirow{6}{*}{ March } & $\operatorname{Min}(\mathrm{mm})$ & 15.30 & 3.20 & 13.20 & 5.70 & 0.60 & 5.10 & 4.90 & 1.50 \\
\hline & $\operatorname{Max}(\mathrm{mm})$ & 266.10 & 297.40 & 271.30 & 186.20 & 259.40 & 247.40 & 348.50 & 210.30 \\
\hline & Avg. (mm) & 94.99 & 62.38 & 103.75 & 65.65 & 73.45 & 71.79 & 88.66 & 67.20 \\
\hline & $\mathrm{SD}(\mathrm{mm})$ & 56.66 & 50.50 & 53.09 & 40.89 & 43.93 & 47.70 & 62.94 & 40.50 \\
\hline & Skewness & 1.47 & 2.24 & 0.84 & 1.19 & 1.66 & 1.33 & 1.73 & 1.15 \\
\hline & Kurtosis & 1.42 & 2.17 & 0.81 & 1.15 & 1.60 & 1.29 & 1.67 & 1.12 \\
\hline \multirow{6}{*}{ April } & Min (mm) & 4.90 & 0.90 & 0.70 & 0.30 & 0.40 & 1.90 & 3.90 & 1.80 \\
\hline & $\operatorname{Max}(\mathrm{mm})$ & 259.60 & 235.60 & 238.50 & 170.00 & 193.90 & 203.10 & 223.90 & 209.00 \\
\hline & Avg. (mm) & 78.33 & 47.27 & 100.07 & 47.05 & 69.27 & 56.35 & 67.98 & 65.13 \\
\hline & $\mathrm{SD}(\mathrm{mm})$ & 56.66 & 41.75 & 53.23 & 34.69 & 41.44 & 43.31 & 45.27 & 44.83 \\
\hline & Skewness & 1.44 & 2.37 & 0.86 & 1.52 & 0.58 & 1.45 & 1.03 & 1.21 \\
\hline & Kurtosis & 1.40 & 2.30 & 0.84 & 1.47 & 0.56 & 1.41 & 1.00 & 1.17 \\
\hline \multirow{6}{*}{ May } & $\operatorname{Min}(\mathrm{mm})$ & 0.00 & 0.00 & 2.00 & 0.00 & 0.00 & 1.40 & 1.80 & 0.00 \\
\hline & $\operatorname{Max}(\mathrm{mm})$ & 196.80 & 109.70 & 291.10 & 95.10 & 192.30 & 126.80 & 146.80 & 152.60 \\
\hline & Avg. (mm) & 41.39 & 25.30 & 60.03 & 25.30 & 41.57 & 30.63 & 37.95 & 41.11 \\
\hline & $\mathrm{SD}(\mathrm{mm})$ & 45.13 & 27.65 & 54.38 & 20.31 & 39.63 & 24.81 & 35.04 & 34.86 \\
\hline & Skewness & 2.10 & 1.36 & 2.02 & 0.94 & 1.88 & 1.44 & 1.68 & 1.14 \\
\hline & Kurtosis & 2.04 & 1.32 & 1.95 & 0.91 & 1.82 & 1.39 & 1.63 & 1.11 \\
\hline \multirow{6}{*}{ June } & $\operatorname{Min}(\mathrm{mm})$ & 0.00 & 0.00 & 0.00 & 0.00 & 0.00 & 0.00 & 0.00 & 0.00 \\
\hline & $\operatorname{Max}(\mathrm{mm})$ & 79.00 & 31.30 & 36.60 & 50.20 & 35.40 & 28.60 & 51.10 & 39.80 \\
\hline & Avg. (mm) & 6.30 & 4.63 & 10.12 & 8.70 & 8.55 & 7.49 & 8.52 & 9.45 \\
\hline & $\mathrm{SD}(\mathrm{mm})$ & 12.41 & 6.06 & 8.59 & 11.60 & 6.84 & 6.91 & 10.26 & 9.92 \\
\hline & Skewness & 4.76 & 2.47 & 1.13 & 2.05 & 1.63 & 1.12 & 2.09 & 1.20 \\
\hline & Kurtosis & 4.61 & 2.40 & 1.09 & 1.99 & 1.58 & 1.09 & 2.02 & 1.16 \\
\hline \multirow{6}{*}{ July } & $\operatorname{Min}(\mathrm{mm})$ & 0.00 & 0.00 & 0.00 & 0.00 & 0.00 & 0.00 & 0.00 & 0.00 \\
\hline & $\operatorname{Max}(\mathrm{mm})$ & 31.00 & 9.70 & 22.20 & 15.00 & 7.50 & 46.00 & 10.50 & 6.10 \\
\hline & Avg. (mm) & 2.10 & 1.09 & 2.56 & 2.15 & 1.06 & 5.06 & 1.55 & 0.80 \\
\hline & $\mathrm{SD}(\mathrm{mm})$ & 4.85 & 1.81 & 3.87 & 3.45 & 1.38 & 8.61 & 2.00 & 0.95 \\
\hline & Skewness & 5.20 & 3.78 & 3.44 & 2.65 & 3.53 & 3.96 & 2.70 & 4.08 \\
\hline & Kurtosis & 5.04 & 3.66 & 3.33 & 2.57 & 3.42 & 3.84 & 2.62 & 3.95 \\
\hline \multirow{2}{*}{ August } & $\operatorname{Min}(\mathrm{mm})$ & 0.00 & 0.00 & 0.00 & 0.00 & 0.00 & 0.00 & 0.00 & 0.00 \\
\hline & $\operatorname{Max}(\mathrm{mm})$ & 7.00 & 26.00 & 13.90 & 80.90 & 13.70 & 75.50 & 16.90 & 3.80 \\
\hline
\end{tabular}




\begin{tabular}{c|c|c|c|c|c|c|c|c|c} 
& Avg. $(\mathrm{mm})$ & 0.79 & 1.43 & 1.68 & 4.60 & 1.14 & 3.59 & 1.14 & 0.54 \\
& SD(mm) & 1.36 & 3.86 & 2.54 & 12.36 & 2.00 & 10.70 & 2.47 & 0.84 \\
& Skewness & 3.77 & 5.90 & 3.20 & 5.59 & 5.64 & 6.73 & 5.80 & 2.95 \\
& Kurtosis & 3.65 & 5.72 & 3.10 & 5.41 & 5.46 & 6.51 & 5.61 & 2.85 \\
\hline \multirow{5}{*}{ September } & Min (mm) & 0.00 & 0.00 & 0.00 & 0.00 & 0.00 & 0.00 & 0.00 & 0.00 \\
& Max (mm) & 15.50 & 83.20 & 35.50 & 48.10 & 38.10 & 54.70 & 44.70 & 68.20 \\
& Avg. (mm) & 2.99 & 4.59 & 5.88 & 6.70 & 4.73 & 8.27 & 6.69 & 5.56 \\
& SD(mm) & 3.36 & 12.37 & 7.10 & 8.96 & 7.24 & 12.65 & 9.62 & 11.09 \\
& Skewness & 2.26 & 5.85 & 2.94 & 2.78 & 3.69 & 2.52 & 2.09 & 4.37 \\
& Kurtosis & 2.19 & 5.66 & 2.85 & 2.69 & 3.58 & 2.44 & 2.02 & 4.24 \\
\hline \multirow{5}{*}{ October } & Min (mm) & 0.10 & 0.00 & 0.80 & 0.30 & 1.30 & 2.30 & 1.00 & 0.00 \\
& Max (mm) & 178.10 & 124.00 & 189.60 & 106.30 & 114.20 & 118.00 & 162.80 & 148.10 \\
& Avg. (mm) & 32.64 & 25.45 & 49.27 & 33.91 & 30.37 & 39.15 & 45.58 & 33.44 \\
& SD(mm) & 36.02 & 29.74 & 43.49 & 26.75 & 25.62 & 30.86 & 37.74 & 33.88 \\
& Skewness & 2.04 & 1.57 & 1.58 & 1.20 & 1.14 & 1.20 & 1.22 & 1.40 \\
& Kurtosis & 1.98 & 1.52 & 1.53 & 1.16 & 1.10 & 1.16 & 1.19 & 1.36 \\
\hline November & Min (mm) & 1.10 & 0.70 & 1.30 & 2.00 & 0.40 & 3.10 & 0.00 & 1.90 \\
& Max (mm) & 189.80 & 187.70 & 213.80 & 179.40 & 146.80 & 214.30 & 232.80 & 123.10 \\
& Avg. (mm) & 69.35 & 46.58 & 81.06 & 58.14 & 53.65 & 66.33 & 73.17 & 53.60 \\
& SD(mm) & 46.98 & 32.78 & 53.02 & 36.80 & 35.17 & 39.20 & 45.53 & 28.33 \\
& Skewness & 0.72 & 1.79 & 0.91 & 1.35 & 1.04 & 1.33 & 1.03 & 0.34 \\
& Kurtosis & 0.70 & 1.74 & 0.88 & 1.31 & 1.01 & 1.29 & 1.00 & 0.33 \\
\hline & Min (mm) & 3.80 & 0.10 & 6.90 & 0.00 & 0.50 & 0.10 & 0.30 & 0.00 \\
& Max (mm) & 337.80 & 179.10 & 278.20 & 196.30 & 162.00 & 259.40 & 331.60 & 162.00 \\
& Avg. (mm) & 103.37 & 71.73 & 86.92 & 81.31 & 63.36 & 94.61 & 125.28 & 70.06 \\
& SD(mm) & 77.51 & 41.57 & 58.45 & 45.55 & 38.93 & 55.12 & 75.71 & 43.56 \\
& Skewness & 1.13 & 0.41 & 1.17 & 0.67 & 0.55 & 1.01 & 0.61 & 0.38 \\
& Kurtosis & 1.10 & 0.40 & 1.13 & 0.65 & 0.53 & 0.98 & 0.59 & 0.36 \\
\hline
\end{tabular}

\section{Standardized precipitation index (SPI)}

The SPI is a powerful index with easy calculation steps as well as flexible time scales (e.g. 1, 3, 6, 12, 24 months). One of the main advantages of SPI is that it use only precipitation data. The index quantifies the precipitation deficit and surplus, taking into account the time series of cumulative precipitation for various reference periods. First, a Gamma distribution (two parametric) is fitted to precipitation data, and then it is transformed into a normal distribution. Therefore, the average of SPI values is 0 , and the standard deviation is 1 . For the studied area and studied period, one can identify the wet and dry conditions in accordance with the classification scale of SPI (Table 3).

It should be noted that, there has been studies which use different statistical distributions (Tsakiris and Vangelis, 2004; Angelidis, 2012), however Guttman (1999) showed that there are only minor differences in the results of SPI with respect to magnitude, duration and extent of drought. Since the SPI is a well-known index, the detailed calculation steps are not given here, however, it can be found in several papers (Mishra and Desai, 2005; Dashtpagerdi et al., 2015). In addition, the SPI software used in this study (SPI_SL_6.exe) could be download from the link given in the WMO (2012). 
Table 3. Classifications scale for SPI values (McKee et al., 1993)

\begin{tabular}{c|c}
\hline SPI values & Drought class \\
\hline $2.00 \leq$ & Extremely wet \\
1.99 to 1.50 & Severely wet \\
1.49 to 1.00 & Moderately wet \\
0.99 to $(-0.99)$ & Near normal \\
$(-1.0)$ to $(-1.49)$ & Moderately dry \\
$(-1.5)$ to $(-1.99)$ & Severely dry \\
$-2.00 \geq$ & Extremely dry \\
\hline
\end{tabular}

\section{Performance indicators (PIs) for the SPI time series}

The PIs are generally used to evaluate water management alternatives and/or to enable the comparison of decisions (Hashimoto et al., 1982). They can be simple averages (e.g. average of deficits), simple ratios (e.g. cost/benefit) and probability of time-based or volume based reliability.

In this study, the SPI-12 (12 month-SPI time series) were evaluated with five PIs defined as reliability, resilience, vulnerability, maximum extent and maximum duration. This procedure can be illustrated by considering any selected indicator $C$, whose time series of values is denoted as $C_{t}$, where the simulated period, $t$, extends to some future time, $T$ (Fig. 2). To define reliability and resilience PIs, a single limit of unsatisfactory is assigned to SPI $\leq 0$ for SPI-12 time series, which demonstrates the deficit from the mean amount of precipitation.

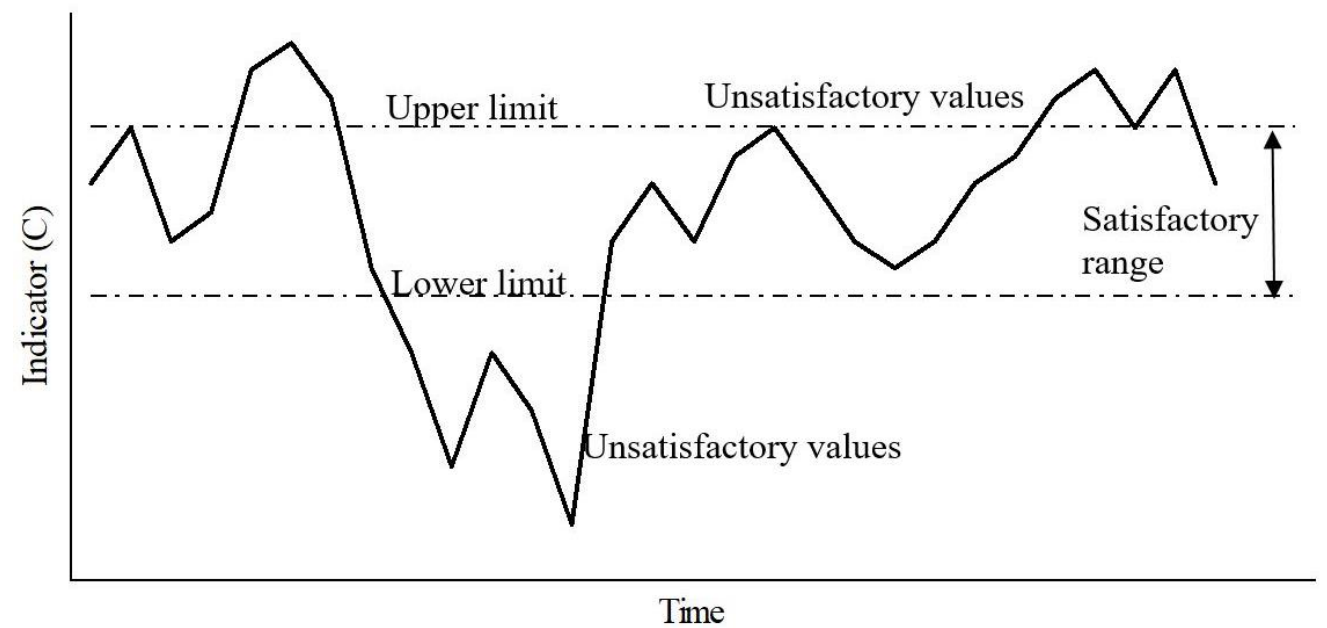

Figure 2. Illustration for reliability, resilience and vulnerability concept

Reliability (REL) is defined as the probability that any particular $C_{t}$ value will be within the range of values considered satisfactory, and is calculated in accordance with Equation 1. 
Resilience (RES) is an indicator describing the speed of recovery from an unsatisfactory condition. It is the probability that a satisfactory value $C_{t+1}$ will follow an unsatisfactory $\mathrm{Ct}$ value, and is calculated according to Equation 2.

$$
\mathrm{RES}=\frac{\text { (Number of times a satisfactory } \mathrm{C}_{\mathrm{t}+1} \text { value follows an unsatisfactory } \mathrm{C}_{\mathrm{t}} \text { value) }}{\text { (Total number of unsatisfactory values, } \mathrm{SPI} \leqslant \text { 0) }}
$$

Although several definitions are possible for the vulnerability (Sandoval-Solis et al., 2011), in this study it is expressed as the probability of exceeding a certain threshold. Here, VUL is obtained by using the following relation that accounts the "drought events" (SPI $\leq-1)$, and "severe and extreme drought events" where the SPI $\leq-1.50$ (Eq. 3).

$$
\mathrm{VUL}=\frac{\text { (Total number of severe and extreme drought events, SPI } \leq 1.5 \text { : }}{\text { (Total number of drought events, SPI } \leq-1.0)}
$$

The maximum extent (ME) of the drought is calculated by dividing the minimum SPI that is experienced in the study period, by $-4(E q .4)$. Here, an assumption is made as the worst-case drought magnitude, SPI $=-4.0$. It should be noted that, it could be determined in accordance with the experts' and decision makers' opinions.

$$
\mathrm{ME}=\frac{(\min \mathrm{SPI} \text { that is experienced in time) }}{\text { (worst-case drought magnitude, assumptive } \mathrm{SPI}=-4.0 \text { ) }}
$$

The maximum duration (MD) is considered as the ratio of maximum duration of continuous droughts to the worst-case drought duration (D), which is accepted as 3 years (36 months) long drought period in this study (Eq. 5). It is thought as a threshold after which the devastating socio-economic effects may occur in agriculture sector.

$$
\mathrm{MD}=\frac{\text { (max duration of continuous droughts) }}{\text { (worst-case drought duration, assumptive } \mathrm{D}=36 \text { months) }}
$$

\section{Drought power index (DPI)}

The DPI can be calculated by combining the REL, RES, VUL, ME and MD indicators as suggested by various researchers (Hashimoto et al., 1982; Sandoval-Solis et al., 2011; Maity et al., 2013). In this study, the DPI is proposed as a geometric average of $M$ performance indicator $\left(C_{m}^{i}\right)$ for the ith province in accordance with Sandoval-Solis et al. (2011) as given in Equation 6.

$$
\mathrm{DPI}_{\mathrm{i}}=\left[\prod_{\mathrm{m}=1}^{\mathrm{M}} \mathrm{C}_{\mathrm{m}}^{\mathrm{i}}\right]^{1 \mathrm{M}}
$$

Here, since the drought is identified as an unfavorable phenomenon, the indicators have to be arranged in accordance to their criteria type (minimizing or maximizing). For example, the reliability indicator is a maximizing indicator even if we calculate sustainability (maximizing reliability is a desired situation). However, in this proposed index where the main aim is to determine the devastating effects of drought with a single numeric (the power of droughts), the reliability is considered as a minimizing indicator. Therefore, the REL indicator is added to the geometric average formula as (1REL). The same approach is applied for all five indicators, and the DPI is defined by 
the following formula (Eq. 7) for the $i^{\text {th }}$ province. The indicator $\left(C_{m}^{i}\right)$ in the below equation must have a scale from $0-1$, and undesirable criteria values tend to 1 . In addition, more indicator can be included in DPI.

$$
\operatorname{DPI}_{\mathrm{i}}=\left[\left(1-\mathrm{REL}^{\mathrm{i}}\right) *\left(1-\mathrm{RES}^{\mathrm{i}}\right) * \mathrm{VUL}^{\mathrm{i}} * \mathrm{ME}^{\mathrm{i}} * \mathrm{MD}^{\mathrm{i}}\right]^{1 / 5}
$$

\section{Decision scale of the DPI}

The DPI is a valuable tool to demonstrate the drought character of the given region. However, a decision scale has to be proposed to evaluate the variations of drought character spatially and temporally. Since the drought power index does not mean the same thing for all water users, the proposed scale is flexible in accordance with the decision makers' preferences. To this end, the personal conversations with the water managers and crop yield experts in SAR are addressed the decision scale with the limits of indicators and the drought character (Table 4).

Table 4. Indicator limits and decision scale

\begin{tabular}{c|c|c|c|c|c|c|c}
\hline Preferences of status & REL & RES & VUL & ME & MD & DPI range & Drought character \\
\hline Very bad & 0.40 & 0.40 & 0.80 & 0.80 & 0.80 & $0.71-1.00$ & Very strong (VS) \\
Bad & 0.50 & 0.50 & 0.60 & 0.60 & 0.60 & $0.56-0.70$ & Strong (S) \\
Normal & 0.70 & 0.70 & 0.40 & 0.40 & 0.40 & $0.36-0.55$ & Normal (N) \\
Good & 0.80 & 0.80 & 0.20 & 0.20 & 0.20 & $0.20-0.35$ & Weak (W) \\
Very good & 1.00 & 1.00 & 0.00 & 0.00 & 0.00 & $0.00-0.19$ & Very weak (VW) \\
\hline
\end{tabular}

\section{Results and discussion}

\section{The assessment of the SPI-12 time series}

The SPI-12 values obtained by the monthly precipitation data corresponding the eight provinces in the SAR are given in Figure 3. As can be seen, the most of year (approx. 70\%) are counted in normal conditions, however the extreme droughts have occurred in 1973-1975 and 2007-2010 periods in almost all provinces. Generally, the basin has experienced severe droughts in 1990-1992 and 2000-2002. It leaps out that record extreme droughts (SPI-12 < -3.0) are monitored at Şanliurfa, Batman and Gaziantep in 1973, at Kilis in 2014 and again at Batman in 2008. The year 1988 can be concluded as an extreme wet year in the basin. The percentile distributions of drought severities were analyzed by dividing the study period in two separate periods, 19701993 and 1970-2017 (Table 5). Although the SPI-12 time series is different from each other, it is possible to say that percentile of total droughts (total of moderate, severe and extreme droughts) has been increased in Mardin, Şanliurfa and Kilis, due to the increasing number of severe and extreme droughts after 1993. Those results are in accordance with the slope of the regression line given in Figure 3.

\section{Assessment of the DPI}

To make an evaluation that base on the log-term drought conditions, the PIs and the DPI scores of each province were calculated (Table 6). The two different evaluation period constitute better understanding the variation in the drought character of the 
provinces. The REL scores are slightly decreasing in the SAR (except Batman and Diyarbakir) that means the annual total precipitation gets less since the time elapsed. The reduction in precipitation amount is more evident in Mardin, where the probability of getting more than average annual precipitation is decreased from 70 to $53 \%$.

The RES is similar for reliability, so the number of continuous droughts is increasing while the individual droughts are decreasing. This is another important result for the region because continuous droughts are more devastating for the socio-economic development in an agricultural dominant region. Again, the decreasing in the resilience indicator is determined significantly for Mardin, and none of the provinces get an increment in that performance indicator.

In this study, the vulnerability measures the percentage of severe and extreme droughts in all drought events. Şanlıurfa, Batman and Adıyaman are in good status from the view of vulnerability. In other words, the severe and extreme droughts are in a shift towards moderate drought in these provinces; however, for the rest of the region, especially in Kilis and Siirt, the opposite is valid.

Table 5. Percentiles of droughts (\%) for 1970-1993 and 1970-2017 periods

\begin{tabular}{|c|c|c|c|c|c|c|c|c|c|c|c|c|c|c|c|c|}
\hline \multirow{2}{*}{ Drght. catg. } & \multicolumn{2}{|c|}{ Mardin } & \multicolumn{2}{|c|}{ Şanlıurfa } & \multicolumn{2}{|c|}{ Siirt } & \multicolumn{2}{|c|}{ Kilis } & \multicolumn{2}{|c|}{ Batman } & \multicolumn{2}{|c|}{ Gaziantep } & \multicolumn{2}{|c|}{ Adıyaman } & \multicolumn{2}{|c|}{ Diyarbakır } \\
\hline & (1) & (2) & (1) & (2) & (1) & (2) & (1) & (2) & (1) & (2) & (1) & (2) & (1) & (2) & (1) & (2) \\
\hline Ext. wet & 4 & 2 & 1 & 3 & 5 & 4 & 1 & 2 & 3 & 2 & 0 & 2 & 1 & 0 & 1 & 1 \\
\hline Sev. wet & 7 & 3 & 5 & 2 & 4 & 2 & 7 & 5 & 2 & 3 & 5 & 3 & 6 & 6 & 6 & 4 \\
\hline Mod. wet & 9 & 7 & 5 & 5 & 3 & 7 & 7 & 10 & 7 & 9 & 9 & 11 & 10 & 15 & 9 & 10 \\
\hline Normal & 68 & 74 & 80 & 76 & 71 & 70 & 70 & 70 & 72 & 70 & 73 & 69 & 69 & 63 & 67 & 68 \\
\hline Mod. dry (a) & 7 & 7 & 3 & 7 & 13 & 10 & 10 & 6 & 9 & 9 & 7 & 8 & 6 & 10 & 11 & 9 \\
\hline Sev. dry (b) & 4 & 3 & 1 & 3 & 3 & 5 & 3 & 4 & 4 & 4 & 1 & 3 & 4 & 4 & 2 & 3 \\
\hline Ext. dry (c) & 1 & 4 & 5 & 4 & 1 & 2 & 2 & 3 & 3 & 3 & 5 & 4 & 4 & 2 & 4 & 5 \\
\hline $\begin{array}{c}\text { Total number of } \\
\text { droughts } \\
(a+b+c)\end{array}$ & 12 & 14 & 9 & 14 & 17 & 17 & 15 & 13 & 16 & 16 & 13 & 15 & 14 & 16 & 17 & 17 \\
\hline
\end{tabular}

(1) $1970-1993,{ }^{(2)} 1970-2017$

Table 6. The PIs and the DPI for 1970-1993 and 1970-2017 periods

\begin{tabular}{c|c|c|c|c|c|c|c|c|c|c|c|c}
\hline Province & REL $^{\mathbf{1}}$ & REL $^{2}$ & RES $^{\mathbf{1}}$ & $\mathbf{R E S}^{\mathbf{2}}$ & $\mathbf{V U L}^{\mathbf{1}}$ & $\mathbf{V U L}^{\mathbf{2}}$ & $\mathbf{M E}^{\mathbf{1}}$ & $\mathbf{M E}^{2}$ & $\mathbf{M D}^{\mathbf{1}}$ & $\mathbf{M D}^{\mathbf{2}}$ & $\mathbf{D P I}^{\mathbf{1}}$ & $\mathbf{D P I}^{\mathbf{2}}$ \\
\hline Mardin & 0.70 & 0.53 & 0.15 & 0.09 & 0.42 & 0.49 & 0.55 & 0.76 & 0.28 & 0.61 & $0.44(\mathrm{~N})$ & $0.63(\mathrm{~S})$ \\
Şanliurfa & 0.58 & 0.54 & 0.20 & 0.14 & 0.71 & 0.51 & 0.83 & 0.86 & 0.28 & 0.33 & $0.56(\mathrm{~S})$ & $0.57(\mathrm{~S})$ \\
Siirt & 0.55 & 0.53 & 0.13 & 0.12 & 0.26 & 0.41 & 0.65 & 0.69 & 0.58 & 0.67 & $0.52(\mathrm{~N})$ & $0.60(\mathrm{~S})$ \\
Kilis & 0.50 & 0.46 & 0.09 & 0.09 & 0.35 & 0.52 & 0.66 & 0.79 & 0.22 & 0.36 & $0.47(\mathrm{~N})$ & $0.59(\mathrm{~S})$ \\
Batman & 0.52 & 0.52 & 0.12 & 0.11 & 0.44 & 0.43 & 0.77 & 0.84 & 0.33 & 0.36 & $0.54(\mathrm{~N})$ & $0.56(\mathrm{~S})$ \\
Gaziantep & 0.58 & 0.53 & 0.15 & 0.14 & 0.44 & 0.49 & 0.85 & 0.83 & 0.25 & 0.33 & $0.51(\mathrm{~N})$ & $0.56(\mathrm{~S})$ \\
Adiyaman & 0.50 & 0.49 & 0.11 & 0.10 & 0.54 & 0.39 & 0.69 & 0.72 & 0.33 & 0.33 & $0.56(\mathrm{~S})$ & $0.53(\mathrm{~N})$ \\
Diyarbakır & 0.51 & 0.53 & 0.12 & 0.12 & 0.38 & 0.48 & 0.66 & 0.72 & 0.31 & 0.58 & $0.51(\mathrm{~N})$ & $0.61(\mathrm{~S})$ \\
\hline
\end{tabular}

${ }^{1} 1970-1993,{ }^{2} 1970-2017,(\mathrm{~N})$ normal, (S) strong 

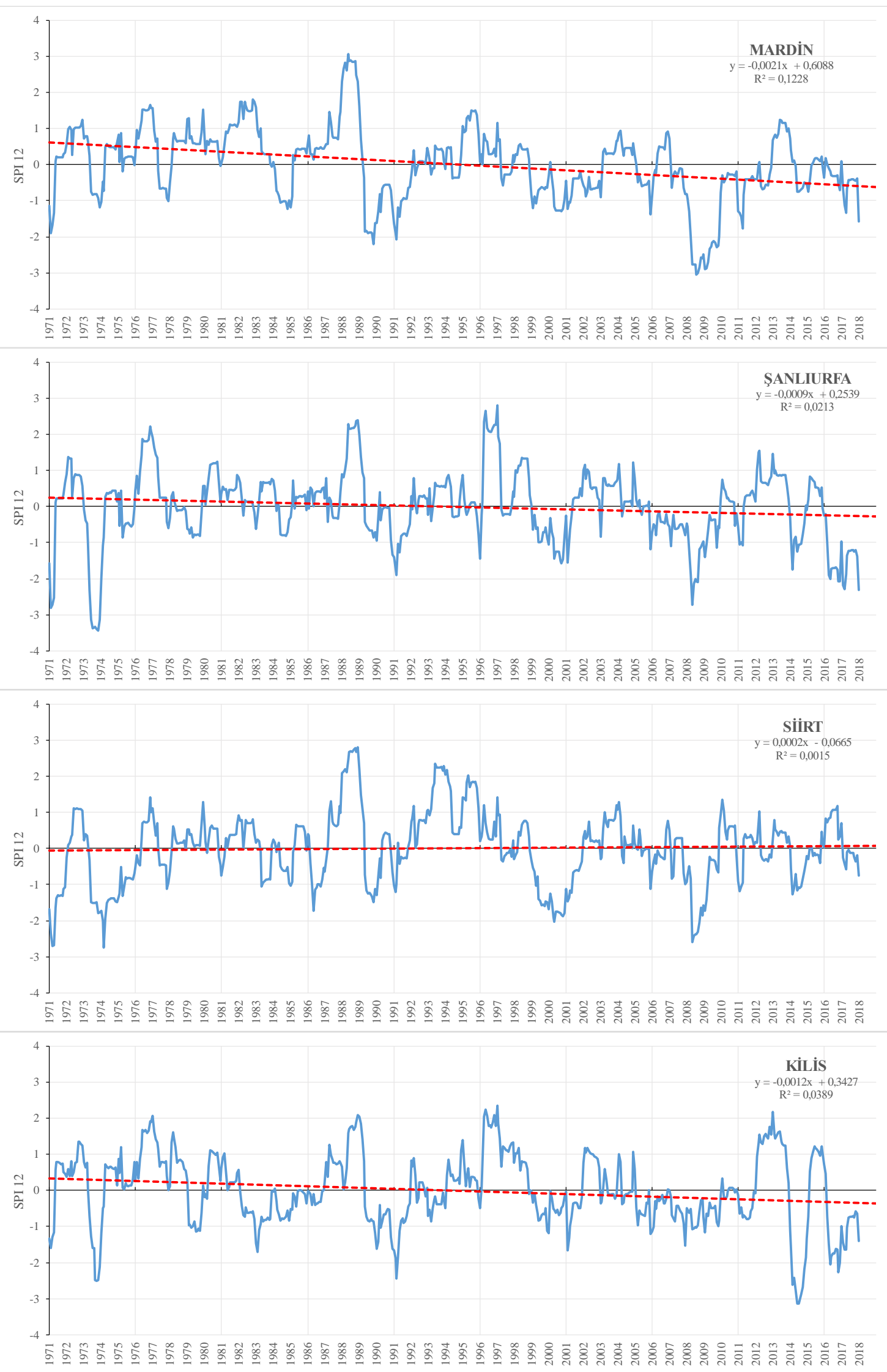

APPLIED ECOLOGY AND ENVIRONMENTAL RESEARCH 16(5):7289-7303.

http://www.aloki.hu • ISSN 15891623 (Print) • ISSN 17850037 (Online)

DOI: http://dx.doi.org/10.15666/aeer/1605_72897303

(c) 2018, ALÖKI Kft., Budapest, Hungary 

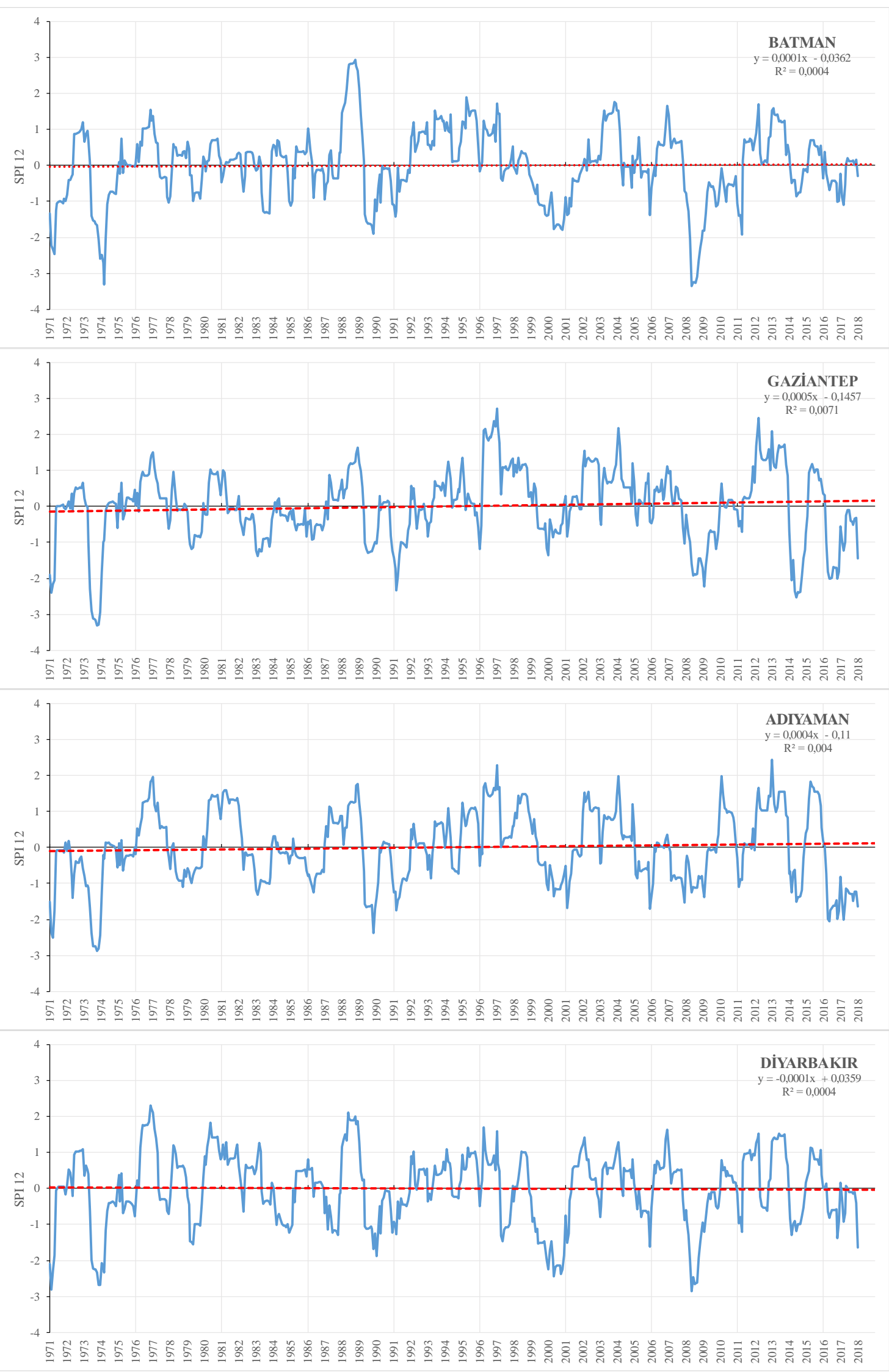

Figure 3. The SPI-12 time series of provinces in SAR 
Şanliurfa, Batman and Gaziantep have the worst scores for the ME due to the minimum SPI-12 values (-3.45), (-3.35) and (-3.31), respectively. Since the worst-case drought magnitude assumed as SPI-12 $=-4.0$, the maximum extent indicator results higher values $0.86,0.84$ and 0.83, respectively. As seen in Figure 3, the extreme droughts have observed in recent years in Batman, Kilis, Mardin and Diyarbakır, and that is why the significant increase in ME for the relevant provinces.

The MD is an important indicator in the proposed index since it detects the longest drought duration relatively. Siirt, Mardin and Diyarbakır has experienced the longest continuous drought durations 24, 22, and 21 months between 1970 and 2017, respectively. Excluding Adiyaman, it is clear from the increasing MD values that the longer droughts have experienced after 1993 for the other provinces.

Considering the end of 2017, the droughts were characterized as strong in seven provinces and normal in Adiyaman. When we compare the DPI values for 1970-1993 and 1970-2017, it is clear that there is an increase in the drought power generally. The DPI increase $43 \%$ and 25\% for Mardin and Kilis, respectively. The ranking of provinces according to DPI scores for (1970-1993) and (1970-2017) revealed interesting results (Table 7). Due to the droughts after 1993, the orders of Mardin and Diyarbakir have moved from bottom to top in the ranking list. Adiyaman seems to lose drought power relative to the first period due to the environmental effects of Atatürk Dam, the biggest dam in Turkey with its $817 \mathrm{~km}^{2}$ reservoir surface and under operation since 1992.

The results of the Southeastern Anatolia Region case which is in line with the findings of other researches (Sönmez et al., 2005; Oruç, 2017) are revealed that the region is under the threat of intense droughts. Moreover, it is obvious that the droughts have gained power after 1993. The increasing in drought power is more evident in Mardin, Diyarbakır, Siirt and Kilis, according to the DPI as well as the DPI rankings. Therefore, starting from these relevant provinces, the more efficient drought management plans integrated with water management policies are needed to overcome or reduce the negative effects of droughts in the region.

Table 7. The DPI rankings of provinces

\begin{tabular}{c|c|c}
\hline Rankings & DPI (1970-1993) & DPI (1970-2017) \\
\hline 1 & Şanlıurfa & Mardin \\
2 & Adıyaman & Diyarbakır \\
3 & Batman & Siirt \\
4 & Siirt & Kilis \\
5 & Gaziantep & Şanlıurfa \\
6 & Diyarbakır & Batman \\
7 & Kilis & Gaziantep \\
8 & Mardin & Adiyaman \\
\hline
\end{tabular}

Before concluding, it is worthwhile to mention here that the most critical factor in the RRV approach is the threshold selection process, as by using a different threshold, the results will be different. In the DPI formulation, a reasonable procedure (regional experts' opinions) is proposed to identify the failure thresholds and the performance limits to obtain the decision scale. More research is needed into choosing the threshold level for different hydroclimatic regions. Towards this aim, sensitivity analysis, which 
was beyond the scope of the present paper, is suggested as a tool to assess the sensitivity of the DPI to different SPI thresholds.

However, the DPI withstand the RRV framework approach, which has the ability to combine and quantify performance indicators. That is a key advantage of the DPI. Moreover, in recent years, more attention is given to the development of hybrid frameworks that could provide more reliable assessments with greater clarity and consistency. With its composite design, the DPI also fits well to that concept also, and can capture the long-term drought characteristics. Additionally, the DPI only needs the precipitation data that are relatively easy to obtain and process. In other words, the DPI also carries the advantages of the SPI.

\section{Conclusions}

In this study, the Drought Power Index (DPI), a modification of widely used SPI with performance indicators, is proposed. It aims to enhance the standardized precipitation index in characterizing drought's devastation power by logging the historical data. The DPI is a single metric to assess the historical drought characteristics base on the given performance indicators. It allows to evaluate the droughts by (i) considering the probability of occurrence, (ii) the speed of recovery once a drought occur, (iii) the relative frequency of severe and extreme droughts, (iv) maximum magnitude of experienced drought and (v) maximum duration of continuous droughts in a single metric. The selection of the time periods in SPI according to growing season of the main crops in the region as well as the decision makers' preferences on threshold values could make the DPI flexible and adaptable for the different drought management policies. Since it characterizes the drought power, it would provide additional insights for the studies dealing with socio-economic droughts, ecologic droughts as well as agricultural risk and insurance.

The presented case study is indicative to represent the DPI. It is noted that the use of the index in different watersheds should provide consensus on the effectiveness and the applicability of the proposed index. Moreover, the main recommendations on this approach include the application of the proposed approach to different time scales of SPI (e.g. monthly, seasonal or crop specific vegetation months for rainfed crops), investigation of the responses of the performance indicators to different SPI thresholds and application of this framework using other drought indices (e.g. Reconnaissance Drought Index). The further studies will reveal conclusions that are more comprehensive, and will help water authorities to assess existing situations, plan for future scenarios, implement processes and thus increase efficiency of the investments.

\section{REFERENCES}

[1] Acikgoz, F. E. (2011): Potential effects of global climate changes on field vegetable growing in the Thrace region. - Journal of Environmental Protection and Ecology 12(1): 240-244.

[2] Angelidis, P., Maris, F., Kotsovinos, N., Hrissanthou, V. (2012): Computation of drought index SPI with alternative distribution functions. - Water Resources Management 26(9): 2453-2473. 
[3] Cancelliere, A., Mauro, G. D., Bonaccorso, B., Rossi, G. (2007): Drought forecasting using the standardized precipitation index. - Water Resources Management 21(5): 801819.

[4] Chen, T., Xia, G., Liu, T., Chen, W., Chi, D. (2016): Assessment of drought impact on main cereal crops using a standardized precipitation evapotranspiration index in Liaoning province, China. - Sustainability 8: 1069. DOI: 10.3390/su8101069

[5] Dashtpagerdi, M. M., Kousari, M. R., Vagharfard, H., Ghonchepour, D., Hosseini, M. E., Ahani, H. (2015): An investigation of drought magnitude trend during 1975-2005 in arid and semi-arid regions of Iran. - Environment Earth Sciences 73(3): 1231-1244.

[6] EPA (Environmental Protection Agency) (2014): Wisconsin Integrated Assessment of Watershed Health. - EPA 841-R-14-001. http://www.epa.gov/healthywatersheds.

[7] GAP (Southeastern Anatolia Project Regional Development Administration) (2018): Latest stage in GAP. - Retrieved from: http://www.gap.gov.tr/gap-ta-son-durum-sayfa32.html\#

[8] Gurel, A., Senel, Z. (2012): Global climate change and adaptations in agriculture. Journal of Environmental Protection and Ecology 13(1): 56-60.

[9] Guttman, N. B. (1999): Accepting the standardized precipitation index: A calculation algorithm. - Journal of the American Water Resources Association 35(2): 311-322.

[10] Hashimoto, T., Stedinger, J. R., Loucks, D. P. (1982): Reliability, resiliency, and vulnerability criteria for water resource system performance evaluation. - Water Resources Research 18(1): 14-20.

[11] Hayes, M. J., Svoboda, M., Wall, N., Widhalm, M. (2011): The Lincoln declaration on drought indices: Universal meteorological drought index recommended. - American Meteorological Society 92(4): 485-488.

[12] Heim, R. R. Jr. (2002): A review of twentieth-century drought indices used in the United States. - American Meteorological Society 83(8): 1149-1165.

[13] Ionita, M., Scholz, P., Chelcea, S. (2016): Assessment of droughts in Romania using the standardized precipitation index. - Natural Hazards 81(3): 1483-1498.

[14] Konyali, S., Kiper, T. (2012): Effect of climate changes on agricultural product quantity and yield and its reflection on sustainable development. The case of the Thrace region. Journal of Environmental Protection and Ecology 13(1): 392-397.

[15] Labudova, L., Labuda, M., Takac, J. (2017): Comparison of SPI and SPEI applicability for drought impact assessment on crop production in the Danubian lowland and the east Slovakian lowland. - Theoretical and Applied Climatology 128(1-2): 491-506.

[16] Livada, I., Assimakopoulos, V. D. (2007): Spatial and temporal analysis of drought in Greece using the standardized precipitation index (SPI). - Theoretical and Applied Climatology 89(3-4): 143-153.

[17] Lloyd-Hughes, B., Saunders, M. A. (2002): A drought climatology for Europe. International Journal of Climatology 22(13): 1571-1592.

[18] Maity, R., Sharma, A., Kumar, D. N., Chanda, K. (2013): Characterizing drought using the reliability-resilience-vulnerability concept. - Journal of Hydrologic Engineering 18(7): 859-869.

[19] Man, T. E., Modra, C. (2008): Drought impact of environment and agricultural products. - Journal of Environmental Protection and Ecology 9(1): 70-76.

[20] Maracchi, G. (2000): Agricultural Drought - A Practical Approach to Definition, Assessment and Mitigation Strategies. - In: Vogt, J. V., Somma, F. (ed.) Drought and Drought Mitigation in Europe. Advances in Natural and Technological Hazards Research. Kluwer Academic Publishers, Dordrecht.

[21] McKee, T. B., Doesken, N. J., Kleist, J. (1993): The relationship of drought frequency and duration to time scales. - Proceedings of the AMS 8th Conference on Applied Climatology, Anaheim, CA, USA, pp. 179-184.

[22] Mishra, A., Desai, V. (2005): Spatial and temporal drought analysis in the Kansabati River basin, India. - International Journal of River Basin Management 3(1): 31-41. 
[23] Oruç. N. (2017): Drought analysis of the Southeast Anatolia Region. - M.Sc. Thesis, Pamukkale University, Institute of Science, Turkey.

[24] Panaitescu, L., Ilie, C., Lungu, M. L., Popescu, M., Lungu, D., Nita, S. (2014): Risk assessment modern approach to the phenomenon of drought and aridity in central and south Dobrudja. - Journal of Environmental Protection and Ecology 15(1): 110-122.

[25] Sandoval-Solis, S., Mckinney, D. C., Loucks, D. P. (2011): Sustainability index for water resources planning and management. - Journal of Water Resources Planning and Management 137(5): 381-390.

[26] Seiler, R. A., Hayes, M., Bressan, L. (2002): Using the standardized precipitation index for flood risk monitoring. - International Journal of Climatology 22(11): 1365-1376.

[27] Shokoohi, A., Morovati, R. (2011): Basinwide comparison of RDI and SPI within an IWRM framework. - Water Resources Management 29(6): 2011-2026.

[28] Sönmez, F. K., Kömüscü, A. Ü., Erkan, A., Turgu, E. (2005): An analysis of spatial and temporal dimension of drought vulnerability in turkey using the standardized precipitation index. - Natural Hazards 35(2): 243-264.

[29] Szalai, S., Szinell, C. (2000): Comparison of Two Drought Indices for Drought Monitoring in Hungary-A case study. - In: Vogt, J. V., Somma, F. (ed.) Drought and Drought Mitigation in Europe. Advances in Natural and Technological Hazards Research. Kluwer Academic Publishers, Dordrecht.

[30] Tate, E. L., Gustard, A. (2000): Drought Definition: A Hydrological Perspective. - In: Vogt, J. V., Somma, F. (ed.) Drought and Drought Mitigation in Europe. Advances in Natural and Technological Hazards Research. Kluwer Academic Publishers, Dordrecht.

[31] Tigkas, D., Vangelis, H., Tsakiris, G. (2018): Drought characterization based on an agriculture-oriented standardized precipitation index. - Theoretical and Applied Climatology. DOI/10.1007/s00704-018-2451-3.

[32] Tsakiris, G., Pangalou, D., Vangelis, H. (2007): Regional drought assessment based on the reconnaissance drought index (RDI). - Water Resources Management 21(5): 821-833.

[33] Tsakiris, G., Vangelis, H. (2004): Towards a drought watch system based on spatial SPI. - Water Resources Management 18(1): 1-12.

[34] Vicente-Serrano, S. M. (2006): Spatial and temporal analysis of droughts in the Iberian Peninsula (1910-2000). - Hydrological Sciences Journal 51(1): 83-97.

[35] Wilhite, D. A., Glantz, M. H. (1985): Understanding the drought phenomenon: the role of definitions. - Water International 10: 111-120.

[36] WMO (World Meteorological Organization). (2012): Standardized Precipitation Index User Guide. - WMO No: 1090, Geneva, Switzerland.

[37] WMO and GWP (World Meteorological Organization and Global Water Partnership). (2016): Handbook of drought indicators and indices. Integrated drought management programme (IDMP), Integrated drought management tools and guidelines series 2, no 1173. - WMO, Geneva, Switzerland.

[38] Zhang, Q., Chong-Yu, X., Zengxin, Z. (2009): Observed changes of drought/wetness episodes in the Pearl River basin, China, using the standardized precipitation index and aridity index. - Theoretical and Applied Climatology 98(1-2): 89-99. 